\title{
Analysis of the development of the wind power industry in China - from the perspective of the financial support
}

\author{
Lin $\mathrm{Wu}^{1}$ and $\mathrm{Han} \mathrm{Li}^{\mathrm{i}^{*}}$
}

\begin{abstract}
Background: The wind energy industry is an important part of the renewable energy industry. Helpful financial support plays an essential role in the process of its development. This study analyzes the financial support efficiency not only from the aspect of capital raise, but also from the aspect of the allocation of up-, middle- and down-stream of the Chinese wind power industry chain (which includes the fan component manufacturing enterprises, the fan production enterprises, the wind farm generation and operation enterprises).
\end{abstract}

Methods: Based on a data envelopment analysis (DEA) model, this study selected 30 representative public companies which sampled and extracted their financial data in a panel analysis from 2010 to 2015, in which the financial support efficiency for the Chinese wind power industry was investigated from the aspect of capital raise and allocation.

Results: In terms of capital raise, the comprehensive efficiencies of these three streams all reached their peak in 2011, and then indicated a slight decline, whereas the fan component manufacturing enterprises had both the largest pure technical efficiency value in 2011 and a relatively high scale efficiency value during the sampling period. In terms of capital allocation, the fan component manufacturing enterprises and the wind farm generation and operation enterprises indicated both the highest comprehensive efficiency in 2011, which is merely the expansion period of the new energy industry. The wind farm generation and operation enterprises showed the lowest pure technical value in 2012, which is also the depression period of the new energy industry. The scale efficiency of the fan production enterprises as well as the wind energy generation and operation enterprises had a relatively high scale efficiency value from 2010 to 2015.

Conclusion: The overall efficiency of financial support in the Chinese wind power industry has a close relationship to the macro-economic environment and capital raise while the allocation efficiency of up-, middle-and down-stream show different characteristics. Moreover, the lag of the core technology is the biggest barrier to the financial support efficiency of the wind power industry.

Keywords: Wind power industry, Financial support, Capital raise, Capital allocation, DEA model

\section{Background}

China is vast in territory of wind energy resources. Wind energy reserves that can be exploited and used are at the forefront of the world. Supporting the fan component manufacturing enterprises vigorously and promoting wind energy integration has been a priority for the development of a new energy strategy in China. After a tireless struggle, within the last 10 years the Chinese wind energy industry

\footnotetext{
* Correspondence: lihan5151@126.com

${ }^{2}$ Business School, Hohai University, Xikang Road 1, Nanjing, Jiangsu 210098,

People's Republic of China

Full list of author information is available at the end of the article
}

has jumped to the top of the world. By the end of 2012, fan manufacturing, wind energy installed capacity and integrated wind energy as a whole in China was the largest in the world [1].

Although China's wind energy industry development has gained gratifying achievements under the haze of financial crisis, the European debt crisis and the global economic slowdown, there were signs of a sharp drop in energy demand at home and abroad, as the wind energy industry was not spared this fate and fell into a long period of adjustment. Since the "Abandon wind" problem is as yet still not understood, growth in the wind 
energy industry has slowed [2]. In the past 2 years, business performance of wind energy enterprises has been generally poor and has entered an era of meager profit.

In order to improve this situation, the ministries and commissions of China have introduced a lot of new energy industry stimulus policies, regulations, standards and guidance catalogs both in the period of "the eleventh fiveyear plan" and "the twelfth five-year plan". With respect to the wind energy industry, it mainly includes taxation policies such as investment subsidies and tax breaks, industry policies such as rationing and forced integration, etc. But as the biggest development bottleneck, the financing problem has not yet been resolved effectively. Thus based on the correlation mechanisms of the finance as well as industry analyses and the industries financial support efficiency, we can determine the efficiency of financing channels and realize the key development bottlenecks of the industry to guide resources, capital, technology and the demand for optimization and agglomeration [3].

Given the background of policy support, this paper uses a data envelopment analysis (DEA) model to study the financial support efficiency for the Chinese wind energy industry from the aspects of capital raise and allocation. In addition, the up-, middle- and down-stream of the wind energy industry chain are analyzed individually. It can be useful to understand the financial support level of each link by comparison in order to achieve more precise conclusions.

The rest of the paper is structured as follows. Methods contains a review of the literature relevant to this topic. Results introduces the DEA model, whereas the methodology and data sources are provided in Conclusions. The results of the empirical application in Chinese wind energy industry are given in Results and discussion, and the last section concludes the paper.

There are many investigations dealing with the capital raise of the wind energy industry. "Aeolus power" (2007) thought that the largest investment in the process of the wind energy project development should be used to purchase wind power units. In order to raise these funds, wind power enterprises should employ the following financing methods: cooperative bank loans, carbon funds, community shares, energy saving trust funds etc. Cory et al. [4] pointed out that wind power enterprises in the USA should create a financing model for the commercial development of wind power projects in 2008.

Following the financial crisis in 2008, existing financing methods for wind power enterprises became imbalanced, and new financing approaches had to be developed. Under this macroscopic background, David [5] suspected that the equipment financing lease had a certain competitive, effectiveness and profitability relative to business borrowing by comparing their residual value structure, complexity and accounting methods; Lee [6] suspected that the American renewable energy development projects could rely on the following three kinds of financing approaches: renewable energy project financing, clean and renewable energy bonds and providing loan guarantees to existing capital markets from the energy departments; Frølunde et al. [7] studied the Danish evaluation method of wind energy enterprises in the project financing process and the conclusions showed that the real option valuation method could provide valuable decision making strategies for managers in wind energy enterprises. Wu [8] suggested that China's wind energy enterprises should gradually achieve transformation from a single financing model to a diversified financing mode; Zhong et al. [9] supposed that the financing methods in wind projects would force wind energy companies to face a higher asset-liability ratio and larger funding pressures, whereas the author put forward the "joint tenant mode of the wind power project financing lease" model, as this model can be implemented to save costs, on the one hand, and does not affect an enterprises preferential Value added tax (VAT) benefit based on commercial loan, on the other.

Apart from capital raise, most of the literature focusses on capital allocation of the wind energy industry. Nikos [10] analyzed the life cycle cost of a wind park and set up a life cycle cost model; Laura et al. [11] put forward a method to evaluate the cost breakdown structure for offshore wind farms.

Some literature studied the financial support of the wind energy industry from a macro perspective. Campoccia et al. [12] presented a comparison of the main support strategies for Wind Farms (Feed-in tariffs and Green Tags), taking into account the situation in some European Countries; Bolinger et al. [13] discussed the limitations of incentives in supporting farmer- or community-owned wind projects and described four ownership structures that potentially overcome such limitations, and finally conducted a comparative financial analysis of those four structures by using a hypothetical 1.5 MW farmer-owned project located in the state of Oregon as an example. Ozkan et al. [14] considered the financial viability of an offshore wind project as dependent on many interrelated factors.

The application of the data envelopment analysis (DEA) for measuring the efficiency of the industrial financial support has widely been used. Emerging strategic industries, such as biotechnology, new energy and advanced equipment manufacturing has often been the research object. For instance, Zhou et al. [15] assessed the performance of China's renewable resource industry from two aspects-the overall industrial development and the listed companies based on the DEA Model. Moreover, Xiong et al. [16] analyzed the financial support efficiency in the new energy, new materials, energy 
conservation and environmental protection industries as the research object was based on the DEA model. Some studies applied the Information Technology industry as the research object, such as Sueyoshi et al. [17], who discussed the use of DEA-DA to assess the corporate value of IT firms. There are plenty of industries which have been studied. For example, Suo et al. [18] utilized the DEA to analyze the importance of financial support in agricultural development; and Tong [19] applied the DEA to assess business performance in the car industry. Pang et al. [20] used the DEA to analyze the efficiency of financial support in a commercial bank.

According to the above literature review, there are plenty of articles which analyze the capital raise and allocation of the wind energy industry. Even though the DEA model has always been widely used, only a few studies refined the industries financial segments to include the up-, middle- and down-stream of the wind energy industry chain. Furthermore, there are only a few studies investigating the financial support efficiency from the aspect of capital raise and allocation. These are therefore the two innovation points claimed in this paper.

\section{Methods}

The DEA method was first put forward by some famous operational research experts. According to Charnes et al. [21], DEA is a non-parametric method for efficiency. The main principle of DEA is to keep the input or output of the decision-making units (DMUs) as the same, and determine not only the relative effective production frontier but also the statistical data by a mathematical programming method. Then, each decision-making unit is projected onto the production frontier, and their relative effectiveness is evaluated by comparing the degree of deviation from the relative effective production frontier. The DEA method does not need to estimate parameters or the hypothesis of the index weight in advance, and is therefore appropriate for border production functions of multi-input and multi-output, and can avoid any deviation caused by the subjectivity which is not eligible for the data dimension. Thus, the DEA model is broadly applicable and has become a very important and effective analysis tool in management science. The basic idea of DEA is shown in Fig. 1.

In Fig. 1, A, B, C, D and E represent the five DMUs. In production activities, each DMU uses the two inputs; $\mathrm{XI}$ and $\mathrm{X} 2$, whereas $\mathrm{Y}$ denotes the output. From Fig. 1 it is evident that $\mathrm{D}$ is the ineffective DMU and the other DMUs are all effective, as they are on the production frontier.

In general, a new efficient DMU can be built through the effective linear combination of the DMU and the production frontier. Taking the DMU D as an example, the intersection point of the $\mathrm{DO}$ line and the production

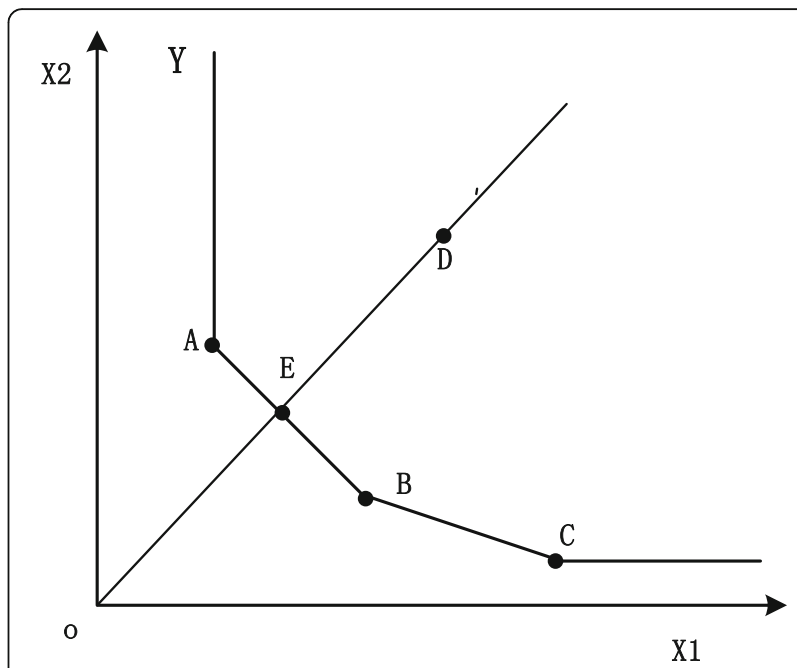

Fig. 1 The basic idea of DEA

frontier is apparently E, which can be described as a linear combination of $\mathrm{A}$ and $\mathrm{B}$. Under the same outputs, the inputs of $E$ are less than $D$. This means that the inputs of $\mathrm{D}$ are higher than $\mathrm{E}$, i.e. they are invalid. At this moment, the efficiency of $\mathrm{E}$ can be described by EO/DO. If EO/DO $<1, \mathrm{D}$ is an invalid DMU and if $\mathrm{EO} / \mathrm{DO}=1, \mathrm{D}$ is a valid DMU. By this way, based on the linear programming model, the DEA can evaluate the relative efficiency of the DMUs.

The DEA model allows for calculating both the allocative efficiency and the technical efficiency, whereas the technical efficiency can be decomposed into scale efficiency and pure technical efficiency. Each model has two forms: an input- and output-oriented one. An outputoriented DEA model is appropriate for calculating the largest output value for a given amount of inputs and the input-oriented DEA model is appropriate for minimizing the cost on a given level of output. The DEA model can be used for a constant return to the scale (CRS) and a variable return to the scale (VRS). The relative efficiency value of decision-making units (DMUs) for the distribution in $(0,1)$ and at the effective forefront value is calculated to be 1 .

The CCR model is the first model of the DEA method named after A. Charnes, W.W. Cooper and E. Rhodes, and is also known as CRS model (constant return to the scale). A CCR model presumes that there are $n$ DMUs whereas each DMU has $m$ types of input and $s$ types of output, whereas vector $x_{j}$ and $y_{j}$ are used to represent the $j$-th DMU: the input vector $x_{j}=\left(x_{1 j}, x_{2 j}, \ldots x_{m j}\right)^{T}$ while the output vector $\mathrm{y}_{j}=\left(\mathrm{y}_{1 j}, \mathrm{y}_{2 j}, \ldots, \mathrm{y}_{\mathrm{s}}\right)^{\mathrm{T}},(i=1,2,3, \ldots \mathrm{n}$.). $\mathrm{x}$ represents the $\mathrm{m} \times \mathrm{n}$ dimensional input matrix and $\mathrm{y}$ represents the $\mathrm{s} \times \mathrm{n}$ dimensional output matrix. It should measure the proportion of all outputs and inputs for each of the DMUs, namely $u^{\prime} y_{i} / v^{\prime} x_{i}$, where $\mathrm{u}$ is the $\mathrm{s} \times 1$ 
dimensional output weight vector and $\mathrm{v}$ is the $\mathrm{m} \times 1$ dimensional input weight vector. When constant returns to the scale are presumed, the optimal weight can be obtained using the following formula:

$$
\begin{array}{ll} 
& \max u, v\left(u^{\prime} y_{i} / v^{\prime} x_{i}\right) \\
\mathrm{s}, \mathrm{t} & u^{\prime} y_{i} / v^{\prime} x_{i} \leq 1 \\
& u, v \geq 0
\end{array} \quad \mathrm{j}=1,2,3, \ldots \mathrm{n}
$$

In order to avoid infinite multiple solutions, the constraint conditions $v^{\prime} x_{i}=1$ are increased, so that formula 1 can be changed to the follow model:

$$
\begin{aligned}
& \max u, v\left(u^{\prime} y_{i} / v^{\prime} x_{i}\right) \\
& v^{\prime} x_{i}=1 \\
& \mathrm{~s}, \mathrm{t} \quad u^{\prime} y_{i} / v^{\prime} x_{i} \leq 1 \quad \mathrm{j}=1,2,3, \ldots \mathrm{n}
\end{aligned}
$$

Therefore, the efficiency of each DMU can be obtained by using the following model:

$$
\begin{array}{lll} 
& \min e-\varepsilon\left(\sum_{\mathrm{i}=1}^{\mathrm{m}} \mathrm{s}_{\mathrm{i}}^{-}+\sum_{\mathrm{r}=1}^{\mathrm{s}} \mathrm{s}_{\mathrm{r}}^{+}\right) \\
\text {s.t. } & \sum_{\mathrm{j}=1}^{\mathrm{n}} \mathrm{x}_{\mathrm{ij}} \lambda_{\mathrm{j}}+\mathrm{s}_{\mathrm{i}}^{-}=\theta \mathrm{x}_{\mathrm{i} 0} \quad \mathrm{i}=1,2, \ldots, m ; \\
& \sum_{j=1}^{n} y_{r j} \lambda_{j}-s_{i}^{+}=y_{r 0} \quad \mathrm{r}=1,2, \ldots, s ; \\
& \lambda_{j}, s_{i}^{-}, s_{r}^{+} \geq 0 \forall i, j, r
\end{array}
$$

where the $s_{i}^{-}$and $s_{r}^{+}$are slack variables, $m$ and $s$ denote the input and output indexes, respectively. $\lambda$ denotes the mix proportion of the $\mathrm{n}$ decision unit in a reformulated and effective DMU, which is relative to $\mathrm{DMU}_{0} . \Theta$ denotes the effective utilization degree of the input, (which is relative to the output in the $\mathrm{DMU}_{0}$ ), which is the efficiency value, indicating whether the financial support is effective in the sample enterprises and whether the output is maximized. $1-\theta$ represents the proportion of an extra investment in the $\mathrm{DMU}_{0}$, namely the maximum investment proportion which can be reduced.

\section{Input-output index selection}

This paper investigates the financial support efficiency for the Chinese wind energy industry from the two aspects of capital raise and allocation. The capital raise efficiency represents the capability of an enterprise to raise funds at the lowest cost through various financing channels in order to support the enterprise operation. Thus, the input-oriented model is adopted to study the capital raise. The capital allocation efficiency is the ability to maximize the output by allocating the given funds to the production and business operation activities of the enterprise. Thus an output-oriented model is adopted to study the capital allocation. The input and output indexes can be found in Table 1.

\section{Data sources and processing}

This paper selects 30 public companies as samples which are from the fan component manufacturing enterprises, the fan production enterprises and the wind farm generation and operation enterprises, respectively, and extracts their financial data as a panel analysis from 2010 to 2015 . The data was primarily sourced from the Shanghai stock exchange and www.hexun.com.

As in the DEA analysis model, the data of input and output cannot be negative, we employed the following formula to normalize the data, which leads to a decline in the value within the scope of $[0.1,1]$ : in the formula (5), where $\mathrm{Z}_{\mathrm{mn}}$ is the $\mathrm{n}$-th indicators'value of the $\mathrm{m}$-th enterprise.

$$
\mathrm{Z}_{\mathrm{mn}}=0.1+\left(\mathrm{Z}_{\mathrm{mn}}-\min \mathrm{Z}_{\mathrm{mn}}\right) /\left(\max \mathrm{Z}_{\mathrm{mn}}-\min \mathrm{Z}_{\mathrm{mn}}\right) \times 0.9
$$

\section{Results and discussion}

\section{The DEA analysis for the efficiency of capital raise}

This paper used the data envelopment analysis program version 2.1(DEAP version 2.1) software to analyze 30 public companies' comprehensive efficiency, i.e. the pure technical efficiency and the scale efficiency of capital raise and allocation in 2010-2015. The comprehensive efficiency also reflected comprehensive measures and an evaluation of the ability of the DMUs in resource allocation and use. Thus, in this paper, the comprehensive efficiency referred to a comprehensive measure for the financial support efficiency of the wind power industry. The pure technical efficiency referred to the production efficiency of the inputs, provided the DMU was on a certain scale. In this paper, the pure technical efficiency referred to a change in the financial support efficiency, which was affected by the management and technology factors of the wind power enterprises. The scale efficiency did reflect the gap between the actual scale and the optimal production scale, whereas in this paper, the

Table 1 The input and output indexes

\begin{tabular}{lll}
\hline $\begin{array}{l}\text { Financial } \\
\text { support }\end{array}$ & Input indexes & Output indexes \\
\hline Capital raise & $\begin{array}{l}\text { asset-liability ratio } \\
\text { the proportion of floating } \\
\text { stocks } \\
\text { beta value }\end{array}$ & $\begin{array}{l}\text { return on equity yearly } \\
\text { operating income growth rate } \\
\text { enterprise total cost }\end{array}$ \\
$\begin{array}{ll}\text { Capital } \\
\text { allocation }\end{array}$ & $\begin{array}{l}\text { asset-liability ratio } \\
\text { the proportion of floating } \\
\text { stocks } \\
\text { beta value }\end{array}$ & $\begin{array}{l}\text { return on equity yearly } \\
\text { operating income growth rate } \\
\text { Tobin Q value }\end{array}$ \\
\hline
\end{tabular}

${ }^{1}$ Tobin $\mathrm{Q}$ value $=$ The company's market value/Asset replacement cost 
scale efficiency referred to the change in the financial support efficiency due to the scale factor of the wind power enterprises.

If the value of the comprehensive efficiency amounted to 1 , it showed that the input and output of this DMU are comprehensive and effective, namely, the technology and the scale were both valid. If the value of the pure technical efficiency amounted to 1 , it showed that the use of its resources was efficient at the present technical level, and the root cause of a value that failed to be comprehensively valid was based on its invalid scale, so that its reform should be focused on how to better represent its scale benefit. If the value of the scale efficiency was 1 , it showed that its scale was valid, however, its technology was invalid and ineffective, and more attention should be given to its technical innovation.

\section{Analysis for the comprehensive efficiency of capital raise} The comprehensive efficiency referred to the product of pure technical efficiency and scale efficiency. Table 2 presents the comprehensive efficiency of capital raise for the sample enterprises from 2010 to 2015 . The data analysis is as follows:

1. The comprehensive efficiency of these three streams all reached their peak in 2011, and then had a slight decline. The fan component manufacturing enterprises and the fan production enterprises are both appearing at their lowest value in 2015 , which was especially true for the fan production enterprises, where the lowest value amounted to only 0.497 . The comprehensive efficiency had however rebounded for the wind farm generation and operation enterprises in 2015, which demonstrated that the capital preferred to enter the construction of the wind farm rather than the production of the fan in these hard times for the development of the wind energy industry.

2. The fan component manufacturing enterprises have the highest comprehensive efficiency value in 2013, where 8 enterprises achieved a comprehensive efficiency of higher than the average value; 2011 was the best year for fan production enterprises, in which the comprehensive efficiency for 8 enterprises reached 1, i.e. the effective comprehensive efficiency. The wind farm generation and operation enterprises included 7 enterprises in 2010, for which the comprehensive efficiency was higher than the average value 0 .

\section{Analysis for the pure technical efficiency of capital raise}

The pure technical efficiency is employed to represent the use efficiency of the inputs, i.e. the higher the value of the pure technical efficiency, the more effective the investment of the project and the higher the efficiency of the company will be. Table 3 presents the pure technical
Table 2 The sample enterprises' comprehensive efficiency of capital raise in 2010-2015

\begin{tabular}{|c|c|c|c|c|c|c|}
\hline \multirow[t]{2}{*}{ Enterprises code } & \multicolumn{6}{|c|}{ Fan Components' Manufacturing Enterprises } \\
\hline & 2010 & 2011 & 2012 & 2013 & 2014 & 2015 \\
\hline 002202 & 0.829 & 0.730 & 0.741 & 0.426 & 1.000 & 1.000 \\
\hline 600875 & 0.357 & 1.000 & 1.000 & 1.000 & 0.534 & 0.238 \\
\hline 600290 & 1.000 & 0.643 & 0.884 & 1.000 & 1.000 & 0.124 \\
\hline 600416 & 0.347 & 1.000 & 1.000 & 0.395 & 0.501 & 0.764 \\
\hline 600112 & 1.000 & 1.000 & 1.000 & 1.000 & 1.000 & 1.000 \\
\hline 000862 & 1.000 & 1.000 & 1.000 & 1.000 & 1.000 & 1.000 \\
\hline 601727 & 1.000 & 1.000 & 1.000 & 1.000 & 1.000 & 1.000 \\
\hline 600089 & 1.000 & 0.576 & 0.457 & 1.000 & 0.864 & 0.171 \\
\hline 002531 & 1.000 & 1.000 & 1.000 & 1.000 & 1.000 & 0.368 \\
\hline 300129 & 1.000 & 1.000 & 0.927 & 1.000 & 1.000 & 0.427 \\
\hline Average & 0.853 & 0.938 & 0.901 & 0.882 & 0.890 & 0.609 \\
\hline \multirow[t]{2}{*}{ Enterprises code } & \multicolumn{6}{|c|}{ Fan Production Enterprises } \\
\hline & 2010 & 2011 & 2012 & 2013 & 2014 & 2015 \\
\hline 600192 & 0.661 & 0.514 & 0.234 & 0.371 & 0.506 & 0.254 \\
\hline 002080 & 0.172 & 1.000 & 0.769 & 0.531 & 0.709 & 0.293 \\
\hline 002201 & 1.000 & 0.539 & 1.000 & 1.000 & 0.716 & 1.000 \\
\hline 002009 & 1.000 & 1.000 & 1.000 & 0.296 & 0.620 & 0.164 \\
\hline 002147 & 1.000 & 1.000 & 1.000 & 1.000 & 1.000 & 1.000 \\
\hline 002122 & 0.276 & 1.000 & 0.268 & 0.232 & 1.000 & 0.033 \\
\hline 600590 & 0.275 & 1.000 & 1.000 & 1.000 & 1.000 & 0.067 \\
\hline 000836 & 1.000 & 1.000 & 0.546 & 1.000 & 1.000 & 0.160 \\
\hline 600629 & 1.000 & 1.000 & 1.000 & 0.535 & 1.000 & 1.000 \\
\hline 000415 & 0.419 & 1.000 & 1.000 & 1.000 & 1.000 & 1.000 \\
\hline Average & 0.680 & 0.905 & 0.782 & 0.696 & 0.855 & 0.497 \\
\hline \multirow[t]{2}{*}{ Enterprises code } & \multicolumn{6}{|c|}{ Wind Farm Generation and Operation Enterprises } \\
\hline & 2010 & 2011 & 2012 & 2013 & 2014 & 2015 \\
\hline 600396 & 0.166 & 1.000 & 0.473 & 1.000 & 0.543 & 0.739 \\
\hline 000539 & 1.000 & 1.000 & 1.000 & 1.000 & 1.000 & 1.000 \\
\hline 000690 & 1.000 & 0.624 & 0.737 & 1.000 & 1.000 & 1.000 \\
\hline 600098 & 1.000 & 0.719 & 0.322 & 0.282 & 0.316 & 0.695 \\
\hline 600605 & 0.709 & 1.000 & 0.170 & 1.000 & 0.558 & 0.370 \\
\hline 600578 & 1.000 & 1.000 & 0.970 & 0.277 & 1.000 & 1.000 \\
\hline 600653 & 1.000 & 0.562 & 1.000 & 0.312 & 0.857 & 0.325 \\
\hline 600795 & 1.000 & 1.000 & 1.000 & 1.000 & 1.000 & 1.000 \\
\hline 000875 & 0.215 & 0.938 & 0.480 & 0.146 & 0.361 & 1.000 \\
\hline 600583 & 1.000 & 1.000 & 1.000 & 1.000 & 1.000 & 1.000 \\
\hline Average & 0.889 & 0.884 & 0.715 & 0.702 & 0.764 & 0.813 \\
\hline
\end{tabular}

efficiency of capital raise for the sample enterprises from 2010 to 2015. The data analysis is as follows:

1.The fan component manufacturing enterprises had the largest efficiency value in 2011, where the value was 0.938 . however, since then, the pure technical 
Table 3 The sample enterprises' pure technical efficiency of capital raise in 2010-2015

\begin{tabular}{|c|c|c|c|c|c|c|}
\hline \multirow[t]{2}{*}{ Enterprises code } & \multicolumn{6}{|c|}{ Fan Components' Manufacturing Enterprises } \\
\hline & 2010 & 2011 & 2012 & 2013 & 2014 & 2015 \\
\hline 002202 & 1.000 & 0.776 & 0.780 & 0.429 & 1.000 & 1.000 \\
\hline 600875 & 0.361 & 1.000 & 1.000 & 1.000 & 0.546 & 0.242 \\
\hline 600290 & 1.000 & 1.000 & 1.000 & 1.000 & 1.000 & 0.329 \\
\hline 600416 & 0.367 & 1.000 & 1.000 & 0.628 & 0.511 & 1.000 \\
\hline 600112 & 1.000 & 1.000 & 1.000 & 1.000 & 1.000 & 1.000 \\
\hline 000862 & 1.000 & 1.000 & 1.000 & 1.000 & 1.000 & 1.000 \\
\hline 601727 & 1.000 & 1.000 & 1.000 & 1.000 & 1.000 & 1.000 \\
\hline 600089 & 1.000 & 0.603 & 0.477 & 1.000 & 0.894 & 0.288 \\
\hline 002531 & 1.000 & 1.000 & 1.000 & 1.000 & 1.000 & 0.379 \\
\hline 300129 & 1.000 & 1.000 & 1.000 & 1.000 & 1.000 & 0.915 \\
\hline Average & 0.873 & 0.938 & 0.926 & 0.906 & 0.895 & 0.715 \\
\hline \multirow[t]{2}{*}{ Enterprises code } & \multicolumn{6}{|c|}{ Fan Production Enterprises } \\
\hline & 2010 & 2011 & 2012 & 2013 & 2014 & 2015 \\
\hline 600192 & 0.805 & 0.559 & 0.391 & 0.467 & 0.510 & 1.000 \\
\hline 002080 & 0.473 & 1.000 & 0.778 & 0.550 & 1.000 & 0.435 \\
\hline 002201 & 1.000 & 0.661 & 1.000 & 1.000 & 1.000 & 1.000 \\
\hline 002009 & 1.000 & 1.000 & 1.000 & 0.410 & 0.696 & 0.436 \\
\hline 002147 & 1.000 & 1.000 & 1.000 & 1.000 & 1.000 & 1.000 \\
\hline 002122 & 0.353 & 1.000 & 0.391 & 0.376 & 1.000 & 0.360 \\
\hline 600590 & 0.311 & 1.000 & 1.000 & 1.000 & 1.000 & 0.350 \\
\hline 000836 & 1.000 & 1.000 & 0.549 & 1.000 & 1.000 & 0.356 \\
\hline 600629 & 1.000 & 1.000 & 1.000 & 0.848 & 1.000 & 1.000 \\
\hline 000415 & 0.493 & 1.000 & 1.000 & 1.000 & 1.000 & 1.000 \\
\hline Average & 0.744 & 0.922 & 0.811 & 0.765 & 0.921 & 0.694 \\
\hline \multirow[t]{2}{*}{ Enterprises code } & \multicolumn{6}{|c|}{ Wind Farm Generation and Operation Enterprises } \\
\hline & 2010 & 2011 & 2012 & 2013 & 2014 & 2015 \\
\hline 600396 & 0.987 & 1.000 & 0.641 & 1.000 & 0.591 & 0.948 \\
\hline 000539 & 1.000 & 1.000 & 1.000 & 1.000 & 1.000 & 1.000 \\
\hline 000690 & 1.000 & 0.979 & 1.000 & 1.000 & 1.000 & 1.000 \\
\hline 600098 & 1.000 & 0.745 & 0.525 & 0.440 & 0.398 & 0.695 \\
\hline 600605 & 0.777 & 1.000 & 0.450 & 1.000 & 0.851 & 0.370 \\
\hline 600578 & 1.000 & 1.000 & 1.000 & 0.307 & 1.000 & 1.000 \\
\hline 600653 & 1.000 & 0.736 & 1.000 & 0.406 & 1.000 & 0.325 \\
\hline 600795 & 1.000 & 1.000 & 1.000 & 1.000 & 1.000 & 1.000 \\
\hline 000875 & 0.462 & 1.000 & 1.000 & 0.415 & 0.876 & 1.000 \\
\hline 600583 & 1.000 & 1.000 & 1.000 & 1.000 & 1.000 & 1.000 \\
\hline Average & 0.923 & 0.946 & 0.862 & 0.757 & 0.872 & 0.928 \\
\hline
\end{tabular}

efficiency value began to drop, leading to a value of only 0.715 in 2015; Relative to the fan component manufacturing enterprises and the wind farm generation and operation enterprises, the pure technical efficiency of the fan production enterprises had a relatively low level during the sample period, whereas this value further dropped to 0.694 in 2015. This indicated that the technology investment efficiency of the fan production enterprises is not high and will affect its capital raise efficiency; the wind farm generation and operation enterprises showed the lowest value in the depression period of the new energy industry, which leads us to the conclusion that it has a close relationship to macro-environment.

2. The fan component manufacturing enterprises have 8 enterprises below the pure technical efficiency from 2010 to 2013 and the fan production enterprises both have 8 enterprises where the effective pure technical efficiency value obtained was 1 in 2011 and 2014. There were only 7 farm generation and operation enterprises which had reached the effective pure technical efficiency in the best year. This suggests that the majority of technology investments by the wind farm generation and operation enterprises did not bring any improvement to the capital raise efficiency.

\section{Analysis of the technical scale efficiency of capital raise}

The scale efficiency presented the appropriateness of the proportion of the aspect of input and output in a period of time. The higher the scale efficiency value is, the more appropriate the scale of the company will be. In Table 4, the scale efficiency of capital raise is listed for the sample enterprises from 2010 to 2015 . The data analysis is as follows:

1. The fan component manufacturing enterprises had a relatively high scale efficiency value during the sampling period, whereas the average value was above 0.8 , indicating that the investment scale of the fan component manufacturing enterprises had a positive impact on the capital raise efficiency. The scale efficiency of the fan production enterprises were fluctuant in 2010-2015, indicating that its investment scale did not attract stable capital. The wind farm generation and operation enterprises reached the largest scale efficiency value in 2011.

2. Among the fan component manufacturing enterprises were 8 enterprises reached the effective pure technical efficiency in 2013. The fan production enterprises included the most (8) companies which had reached the effective scale technical efficiency in 2011. There were only 6 wind farm generation and operation enterprises which had reached the effective scale technical efficiency in the best year. This showed that the investment scale of the majority of wind farm generation and operation enterprises did not bring any improvement in the capital raise efficiency. 
Table 4 The sample enterprises' scale efficiency of capital raise in 2010-2015

\begin{tabular}{|c|c|c|c|c|c|c|}
\hline \multirow[t]{2}{*}{ Enterprises code } & \multicolumn{6}{|c|}{ Fan Components' Manufacturing Enterprises } \\
\hline & 2010 & 2011 & 2012 & 2013 & 2014 & 2015 \\
\hline 002202 & 0.829 & 0.942 & 0.951 & 0.993 & 1.000 & 1.000 \\
\hline 600875 & 0.989 & 1.000 & 1.000 & 1.000 & 0.977 & 0.982 \\
\hline 600290 & 1.000 & 0.643 & 0.884 & 1.000 & 1.000 & 0.377 \\
\hline 600416 & 0.946 & 1.000 & 1.000 & 0.629 & 0.981 & 0.764 \\
\hline 600112 & 1.000 & 1.000 & 1.000 & 1.000 & 1.000 & 1.000 \\
\hline 000862 & 1.000 & 1.000 & 1.000 & 1.000 & 1.000 & 1.000 \\
\hline 601727 & 1.000 & 1.000 & 1.000 & 1.000 & 1.000 & 1.000 \\
\hline 600089 & 1.000 & 0.955 & 0.957 & 1.000 & 0.967 & 0.593 \\
\hline 002531 & 1.000 & 1.000 & 1.000 & 1.000 & 1.000 & 0.971 \\
\hline 300129 & 1.000 & 1.000 & 0.927 & 1.000 & 1.000 & 0.466 \\
\hline Average & 0.976 & 0.954 & 0.972 & 0.962 & 0.992 & 0.815 \\
\hline \multirow[t]{2}{*}{ Enterprises code } & \multicolumn{6}{|c|}{ Fan Production Enterprises } \\
\hline & 2010 & 2011 & 2012 & 2013 & 2014 & 2015 \\
\hline 600192 & 0.821 & 0.919 & 0.599 & 0.795 & 0.992 & 0.254 \\
\hline 002080 & 0.363 & 1.000 & 0.988 & 0.965 & 0.709 & 0.673 \\
\hline 002201 & 1.000 & 0.815 & 1.000 & 1.000 & 0.716 & 1.000 \\
\hline 002009 & 1.000 & 1.000 & 1.000 & 0.720 & 0.892 & 0.376 \\
\hline 002147 & 1.000 & 1.000 & 1.000 & 1.000 & 1.000 & 1.000 \\
\hline 002122 & 0.782 & 1.000 & 0.685 & 0.617 & 1.000 & 0.091 \\
\hline 600590 & 0.883 & 1.000 & 1.000 & 1.000 & 1.000 & 0.191 \\
\hline 000836 & 1.000 & 1.000 & 0.994 & 1.000 & 1.000 & 0.448 \\
\hline 600629 & 1.000 & 1.000 & 1.000 & 0.631 & 1.000 & 1.000 \\
\hline 000415 & 0.850 & 1.000 & 1.000 & 1.000 & 1.000 & 1.000 \\
\hline Average & 0.870 & 0.973 & 0.927 & 0.873 & 0.931 & 0.603 \\
\hline \multirow[t]{2}{*}{ Enterprises code } & \multicolumn{6}{|c|}{ Wind Farm Generation and Operation Enterprises } \\
\hline & 2010 & 2011 & 2012 & 2013 & 2014 & 2015 \\
\hline 600396 & 0.168 & 1.000 & 0.738 & 1.000 & 0.919 & 0.780 \\
\hline 000539 & 1.000 & 1.000 & 1.000 & 1.000 & 1.000 & 1.000 \\
\hline 000690 & 1.000 & 0.637 & 0.737 & 1.000 & 1.000 & 1.000 \\
\hline 600098 & 1.000 & 0.966 & 0.613 & 0.641 & 0.794 & 0.913 \\
\hline 600605 & 0.913 & 1.000 & 0.378 & 1.000 & 0.656 & 0.650 \\
\hline 600578 & 1.000 & 1.000 & 0.970 & 0.902 & 1.000 & 1.000 \\
\hline 600653 & 1.000 & 0.763 & 1.000 & 0.768 & 0.857 & 0.325 \\
\hline 600795 & 1.000 & 1.000 & 1.000 & 1.000 & 1.000 & 1.000 \\
\hline 000875 & 0.466 & 0.938 & 0.480 & 0.352 & 0.412 & 1.000 \\
\hline 600583 & 1.000 & 1.000 & 1.000 & 1.000 & 1.000 & 1.000 \\
\hline Average & 0.855 & 0.930 & 0.792 & 0.866 & 0.864 & 0.867 \\
\hline
\end{tabular}

DEA analysis for the efficiency of capital allocation

This paper used the DEAP Version 2.1 software to analyze the comprehensive efficiency, the pure technical efficiency and the scale efficiency of capital allocation in 2010-2015.

\section{Analysis of the comprehensive efficiency of capital} allocation

Table 5 illustrates the comprehensive efficiency of capital allocation for the sample enterprises from 2010 to 2015. The data analysis is as follows:

Table 5 The sample enterprises' comprehensive efficiency of capital allocation in 2010-2015

Enterprises code Fan Components' Manufacturing Enterprises

$\begin{array}{lllllll} & 2010 & 2011 & 2012 & 2013 & 2014 & 2015 \\ 002202 & 0.780 & 0.668 & 0.455 & 0.700 & 1.000 & 1.000 \\ 600875 & 0.342 & 1.000 & 1.000 & 1.000 & 0.576 & 0.804 \\ 600290 & 0.773 & 0.849 & 0.437 & 0.688 & 0.791 & 0.552 \\ 600416 & 0.232 & 0.362 & 0.393 & 0.641 & 0.731 & 0.915 \\ 600112 & 1.000 & 1.000 & 1.000 & 1.000 & 1.000 & 1.000 \\ 000862 & 0.239 & 0.606 & 0.256 & 0.739 & 1.000 & 0.872 \\ 601727 & 1.000 & 1.000 & 0.848 & 1.000 & 0.777 & 0.253 \\ 600089 & 0.342 & 1.000 & 0.833 & 0.875 & 0.761 & 0.556 \\ 002531 & 1.000 & 1.000 & 1.000 & 1.000 & 1.000 & 1.000 \\ 300129 & 1.000 & 1.000 & 0.806 & 1.000 & 1.000 & 0.610 \\ \text { Average } & 0.671 & 0.848 & 0.703 & 0.864 & 0.863 & 0.756\end{array}$

Enterprises code Fan Production Enterprises

\begin{tabular}{|c|c|c|c|c|c|c|}
\hline & 2010 & 2011 & 2012 & 2013 & 2014 & 2015 \\
\hline 600192 & 0.579 & 1.000 & 1.000 & 1.000 & 1.000 & 0.320 \\
\hline 002080 & 0.742 & 1.000 & 1.000 & 0.760 & 0.947 & 1.000 \\
\hline 002201 & 0.637 & 0.431 & 0.908 & 0.601 & 0.898 & 0.346 \\
\hline 2009 & 0.759 & 0.409 & 1.000 & 1.000 & 0.978 & 525 \\
\hline 2147 & 1.000 & 1.000 & 1.000 & 0.999 & 0.925 & .000 \\
\hline 2122 & 0.490 & 0.584 & 1.000 & 0.852 & 1.000 & 410 \\
\hline 0590 & 1.000 & 0.299 & 0.690 & 0.566 & 0.874 & 0.410 \\
\hline 0836 & 1.000 & 1.000 & 0.894 & 0.591 & 1.000 & .979 \\
\hline 600629 & 1.000 & 0.779 & 1.000 & 1.000 & 1.000 & 1.000 \\
\hline 0415 & 0.482 & 1.000 & 1.000 & 1.000 & 1.000 & 0.328 \\
\hline Average & 0.769 & 0.750 & 0.949 & 0.837 & 0.962 & 0.632 \\
\hline \multirow[t]{2}{*}{ Enterprises code } & \multicolumn{6}{|c|}{ Wind Farm Generation and Operation Enterprises } \\
\hline & 2010 & 2011 & 2012 & 2013 & 2014 & 2015 \\
\hline 0396 & 0.053 & 1.000 & 0.571 & 1.000 & 0.955 & 0.989 \\
\hline 0539 & 1.000 & 1.000 & 1.000 & 1.000 & 1.000 & 1.000 \\
\hline 0690 & 1.000 & 0.780 & 1.000 & 1.000 & 1.000 & 1.000 \\
\hline 0098 & 1.000 & 1.000 & 0.516 & 0.456 & 0.478 & 0.851 \\
\hline 0605 & 1.000 & 1.000 & 1.000 & 1.000 & 1.000 & 1.000 \\
\hline 0578 & 0.471 & 1.000 & 1.000 & 1.000 & 1.000 & 1.000 \\
\hline 0653 & 0.557 & 0.880 & 0.680 & 0.555 & 0.561 & 0.456 \\
\hline 0795 & 0.489 & 1.000 & 0.552 & 0.552 & 0.552 & 0.526 \\
\hline 0875 & 0.185 & 1.000 & 0.280 & 0.276 & 0.306 & 0.363 \\
\hline 0583 & 1.000 & 0.943 & 1.000 & 1.000 & 1.000 & 1.000 \\
\hline Average & 0.675 & 0.960 & 0.760 & 0.784 & 0.785 & 0.818 \\
\hline
\end{tabular}


1. The fan component manufacturing enterprises include most enterprises that reached the comprehensive effective efficiency in 2011 as well as the wind farm generation and operation enterprises with the highest comprehensive efficiency value in 2011, which comprises the expansion period of the new energy industry, indicating that a good macro-environment can improve the efficiency of capital allocation. The comprehensive efficiency of the fan production enterprises were fluctuant in 2010-2015; The wind farm generation and operation enterprises showed a higher comprehensive efficiency in 2011 than in other years, where the comprehensive efficiencies of 7 enterprises were higher, i.e. showed a higher level than the average value.

2. Most of the fan component manufacturing enterprises were not below the effective comprehensive efficiency during the sampling period, with only 3 in 2015. The fan production enterprises included 7 companies that had reached the effective comprehensive efficiency in 2012, i.e. there were more than 5 wind farm generation and operation enterprises below the effective comprehensive efficiency from 2010 to 2015.

\section{Analysis for the pure technical efficiency of capital allocation}

In Table 6, the pure technical efficiency of capital allocation for the sample enterprises from 2010 to 2015 is presented. The data analysis is as follows:

1. The fan component manufacturing enterprises had the largest pure technical efficiency value in 2010, where it reached 0.965 . Subsequently, the pure technical efficiency value began to drop, and the lowest value appeared in 2012, and afterwards the efficiency value began to rebound. This shows that the fan component manufacturing enterprises are trying to improve the efficiency of capital allocation through the investment of technology following an industrial recession. The pure technical efficiency of the fan production enterprises remain in an upward trend from 2010 to 2014, however, a sharp fall was observed in 2015, where the wind farm generation and operation enterprises reached the lowest value in the depression period of the new energy industry, which indicated a close relationship to the macro-environment.

2. The fan component manufacturing enterprises included 7 enterprises below the effective pure technical efficiency in 2010 and 2015, and among the fan production enterprises were the most numbers of enterprises with a pure technical efficiency value of 1 . In 2014, this were 8 enterprises.
Table 6 The sample enterprises' pure technical efficiency of capital allocation in 2010-2015

\begin{tabular}{|c|c|c|c|c|c|c|}
\hline \multirow[t]{2}{*}{ Enterprises code } & \multicolumn{6}{|c|}{ Fan Components' Manufacturing Enterprises } \\
\hline & 2010 & 2011 & 2012 & 2013 & 2014 & 2015 \\
\hline 002202 & 1.000 & 0.668 & 0.546 & 0.758 & 1.000 & 1.000 \\
\hline 600875 & 0.909 & 1.000 & 1.000 & 1.000 & 0.632 & 0.829 \\
\hline 600290 & 1.000 & 0.911 & 0.500 & 0.866 & 0.941 & 1.000 \\
\hline 600416 & 1.000 & 0.578 & 0.500 & 0.758 & 0.884 & 1.000 \\
\hline 600112 & 1.000 & 1.000 & 1.000 & 1.000 & 1.000 & 1.000 \\
\hline 000862 & 0.882 & 0.701 & 0.339 & 0.765 & 1.000 & 1.000 \\
\hline 601727 & 1.000 & 1.000 & 0.849 & 1.000 & 0.824 & 0.253 \\
\hline 600089 & 0.858 & 1.000 & 0.869 & 1.000 & 0.864 & 0.624 \\
\hline 002531 & 1.000 & 1.000 & 1.000 & 1.000 & 1.000 & 1.000 \\
\hline 300129 & 1.000 & 1.000 & 0.810 & 1.000 & 1.000 & 1.000 \\
\hline Average & 0.965 & 0.886 & 0.741 & 0.915 & 0.915 & 0.871 \\
\hline \multirow[t]{2}{*}{ Enterprises code } & \multicolumn{6}{|c|}{ Fan Production Enterprises } \\
\hline & 2010 & 2011 & 2012 & 2013 & 2014 & 2015 \\
\hline 600192 & 0.740 & 1.000 & 1.000 & 1.000 & 1.000 & 0.358 \\
\hline 002080 & 0.957 & 1.000 & 1.000 & 0.777 & 1.000 & 1.000 \\
\hline 002201 & 0.919 & 0.648 & 0.939 & 0.723 & 0.954 & 0.537 \\
\hline 002009 & 1.000 & 0.600 & 1.000 & 1.000 & 1.000 & 0.551 \\
\hline 002147 & 1.000 & 1.000 & 1.000 & 1.000 & 1.000 & 1.000 \\
\hline 002122 & 0.712 & 0.625 & 1.000 & 1.000 & 1.000 & 0.474 \\
\hline 600590 & 1.000 & 0.492 & 0.714 & 0.591 & 0.915 & 0.459 \\
\hline 000836 & 1.000 & 1.000 & 0.912 & 0.627 & 1.000 & 1.000 \\
\hline 600629 & 1.000 & 0.888 & 1.000 & 1.000 & 1.000 & 1.000 \\
\hline 000415 & 0.482 & 1.000 & 1.000 & 1.000 & 1.000 & 0.350 \\
\hline Average & 0.769 & 0.825 & 0.957 & 0.872 & 0.987 & 0.673 \\
\hline \multirow[t]{2}{*}{ Enterprises code } & \multicolumn{6}{|c|}{ Wind Farm Generation and Operation Enterprises } \\
\hline & 2010 & 2011 & 2012 & 2013 & 2014 & 2015 \\
\hline 600396 & 0.057 & 1.000 & 0.629 & 1.000 & 1.000 & 1.000 \\
\hline 000539 & 1.000 & 1.000 & 1.000 & 1.000 & 1.000 & 1.000 \\
\hline 000690 & 1.000 & 0.782 & 1.000 & 1.000 & 1.000 & 1.000 \\
\hline 600098 & 1.000 & 1.000 & 0.548 & 0.475 & 0.484 & 1.000 \\
\hline 600605 & 1.000 & 1.000 & 1.000 & 1.000 & 1.000 & 1.000 \\
\hline 600578 & 1.000 & 1.000 & 1.000 & 1.000 & 1.000 & 1.000 \\
\hline 600653 & 0.593 & 0.922 & 0.765 & 0.559 & 0.595 & 0.463 \\
\hline 600795 & 0.643 & 1.000 & 0.686 & 0.686 & 0.686 & 0.593 \\
\hline 000875 & 0.218 & 1.000 & 0.337 & 0.337 & 0.337 & 0.367 \\
\hline 600583 & 1.000 & 1.000 & 1.000 & 1.000 & 1.000 & 1.000 \\
\hline Average & 0.751 & 0.970 & 0.796 & 0.806 & 0.810 & 0.970 \\
\hline
\end{tabular}

There are, in general, more wind farm generation and operation enterprises, which had reached the effective pure technical efficiency compared to the other two types of enterprises, where 38 enterprises were below the effective pure technical efficiency 
from 2010 to 215 . This indicated that the technology investment of the majority of wind farm generation and operation enterprises was able to optimize the configuration of funds.

\section{Analysis for the scale efficiency of capital allocation} In Table 7, the scale efficiency of capital allocation is listed for sample enterprises from 2010 to 2015. The data analysis is as follows:

1. The fan component manufacturing enterprises had a relatively low scale efficiency value during the sampling period, in which low values were found in 2010 and 2015. 2010 is the year in which the wind energy industry expanded rapidly, whereas 2015 is the year in which the wind energy industry produced excess capacity. This shows that its investment scale has a great influence on the efficiency of capital allocation. The scale efficiency of the fan production enterprises and the wind energy generation and operation enterprises both had a relatively high scale efficiency value from 2010 to 2015 , which indicated that their investment scale was appropriate for capital allocation efficiency.

2. Most of the fan component manufacturing enterprises did not reach the effective pure technical efficiency from 2010 to 2015, which was reached by only 6 in the best year. In this period of time, the fan production enterprises included the highest number of enterprises with a pure technical efficiency value of 1 , which were 7 in 2012. The best year for the wind farm generation and operation enterprises was 2011, where only 7 enterprises were below the effective pure technical efficiency.

\section{Comparative analysis of the financial support efficiency}

This paper compares the comprehensive efficiency, the pure technical efficiency and the scale efficiency of capital raise and allocation of 30 public companies from 2010 to 2015.

\section{Comparative analysis of capital raise efficiency}

Figure 2 shows the comparative analysis with regard to the capital raise efficiency. The analysis of the results is as follows:

1. For the fan component manufacturing enterprises, the comprehensive efficiency value showed a slight change when the scale efficiency value showed a sharp rise; the pure technical efficiency was less than the scale efficiency within each year. This means that the capital raise efficiency of the fan component manufacturing enterprises is highly correlated with technology investment.
Table 7 The sample enterprises' scale efficiency of capital allocation in 2010-2015

\begin{tabular}{|c|c|c|c|c|c|c|}
\hline \multirow[t]{2}{*}{ Enterprises code } & \multicolumn{6}{|c|}{ Fan Components' Manufacturing Enterprises } \\
\hline & 2010 & 2011 & 2012 & 2013 & 2014 & 2015 \\
\hline 002202 & 0.780 & 0.999 & 0.834 & 0.924 & 1.000 & 1.000 \\
\hline 600875 & 0.376 & 1.000 & 1.000 & 1.000 & 0.911 & 0.970 \\
\hline 600290 & 0.773 & 0.932 & 0.874 & 0.795 & 0.840 & 0.552 \\
\hline 600416 & 0.232 & 0.627 & 0.786 & 0.845 & 0.826 & 0.915 \\
\hline 600112 & 1.000 & 1.000 & 1.000 & 1.000 & 1.000 & 1.000 \\
\hline 000862 & 0.271 & 0.863 & 0.754 & 0.966 & 1.000 & 0.872 \\
\hline 601727 & 1.000 & 1.000 & 0.999 & 1.000 & 0.942 & 1.000 \\
\hline 600089 & 0.398 & 1.000 & 0.959 & 0.875 & 0.880 & 0.892 \\
\hline 002531 & 1.000 & 1.000 & 1.000 & 1.000 & 1.000 & 1.000 \\
\hline 300129 & 1.000 & 1.000 & 0.995 & 1.000 & 1.000 & 0.610 \\
\hline Average & 0.683 & 0.942 & 0.920 & 0.940 & 0.940 & 0.881 \\
\hline \multirow[t]{2}{*}{ Enterprises code } & \multicolumn{6}{|c|}{ Fan Production Enterprises } \\
\hline & 2010 & 2011 & 2012 & 2013 & 2014 & 2015 \\
\hline 600192 & 0.782 & 1.000 & 1.000 & 1.000 & 1.000 & 0.894 \\
\hline 002080 & 0.775 & 1.000 & 1.000 & 0.978 & 0.947 & 1.000 \\
\hline 002201 & 0.693 & 0.665 & 0.967 & 0.831 & 0.941 & 0.645 \\
\hline 002009 & 0.759 & 0.681 & 1.000 & 1.000 & 0.978 & 0.954 \\
\hline 002147 & 1.000 & 1.000 & 1.000 & 0.999 & 0.925 & 1.000 \\
\hline 002122 & 0.687 & 0.934 & 1.000 & 0.852 & 1.000 & 0.865 \\
\hline 600590 & 1.000 & 0.608 & 0.966 & 0.958 & 0.955 & 0.895 \\
\hline 000836 & 1.000 & 1.000 & 0.980 & 0.943 & 1.000 & 0.979 \\
\hline 600629 & 1.000 & 0.877 & 1.000 & 1.000 & 1.000 & 1.000 \\
\hline 000415 & 0.661 & 1.000 & 1.000 & 1.000 & 1.000 & 0.937 \\
\hline Average & 0.836 & 0.876 & 0.991 & 0.956 & 0.975 & 0.917 \\
\hline \multirow[t]{2}{*}{ Enterprises code } & \multicolumn{6}{|c|}{ Wind Farm Generation and Operation Enterprises } \\
\hline & 2010 & 2011 & 2012 & 2013 & 2014 & 2015 \\
\hline 600396 & 0.923 & 1.000 & 0.909 & 1.000 & 0.955 & 0.989 \\
\hline 000539 & 1.000 & 1.000 & 1.000 & 1.000 & 1.000 & 1.000 \\
\hline 000690 & 1.000 & 0.997 & 1.000 & 1.000 & 1.000 & 1.000 \\
\hline 600098 & 1.000 & 1.000 & 0.940 & 0.959 & 0.987 & 0.851 \\
\hline 600605 & 1.000 & 1.000 & 1.000 & 1.000 & 1.000 & 1.000 \\
\hline 600578 & 0.471 & 1.000 & 1.000 & 1.000 & 1.000 & 1.000 \\
\hline 600653 & 0.939 & 0.954 & 0.890 & 0.992 & 0.943 & 0.985 \\
\hline 600795 & 0.760 & 1.000 & 0.805 & 0.805 & 0.805 & 0.887 \\
\hline 000875 & 0.848 & 1.000 & 0.832 & 0.820 & 0.909 & 0.989 \\
\hline 600583 & 1.000 & 0.943 & 1.000 & 1.000 & 1.000 & 1.000 \\
\hline Average & 0.894 & 0.989 & 0.938 & 0.958 & 0.960 & 0.970 \\
\hline
\end{tabular}

2. For the fan production enterprises, the comprehensive efficiency value indicated the same change trend as the pure technical efficiency value and the scale efficiency value, whereas the pure technical efficiency was always less than the scale 


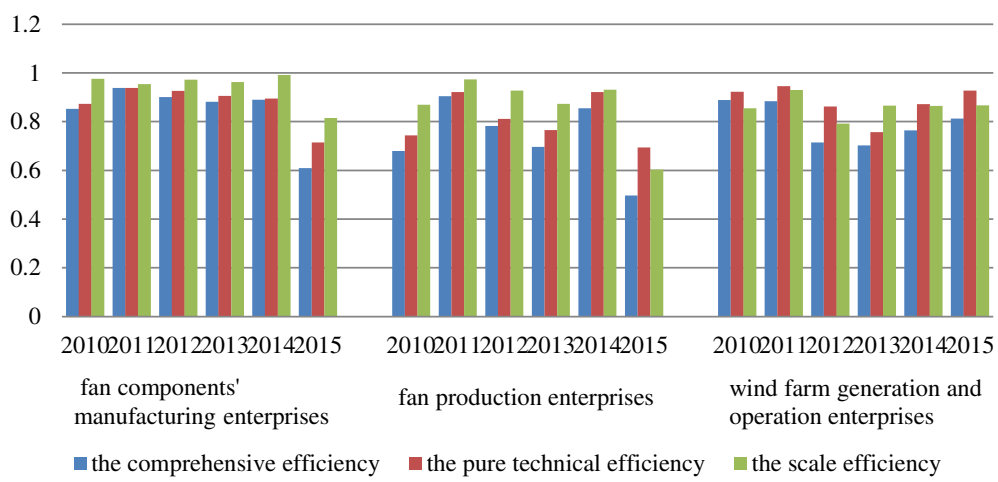

Fig. 2 Comparative analysis of the efficiency on capital raise

efficiency. This showed that the fan production enterprises should focus on technology investment in order to improve the capital raise efficiency.

3. For the wind farm generation and operation enterprises, the comprehensive efficiency value indicated the same change trend as the pure technical efficiency value and the scale efficiency value, whereas the scale efficiency is consistently less than the pure technical efficiency. These results tell us that the investment scale is the main factor, which significantly affects the wind farm generation and operation enterprises.

\section{Comparative analysis of the capital allocation efficiency}

Figure 3 presents a comparative analysis with regard to the capital allocation efficiency. The analysis of the results is as follows:

1. For the fan component manufacturing enterprises, the scale efficiency remained "almost flat" during the sampling period, as the change of the comprehensive efficiency is mainly based upon a change in the pure technical efficiency, whereas the pure technical efficiency is below the scale efficiency most of the time. This means that the capital allocation efficiency of the fan component manufacturing enterprises is highly correlating with technology investment.

2. For the fan production enterprises, the comprehensive efficiency value indicated the same change trend as the pure technical efficiency value, whereas the pure technical efficiency was, for the most part, below the scale efficiency. This showed that the fan production enterprises should focus on technology investment in order to improve the capital raise efficiency.

3. For the wind farm generation and operation enterprises, the scale efficiency remained flat from 2012 to 2015, whereas a change of the comprehensive efficiency was mainly based upon a change in the pure technical efficiency. These results tell us that the wind farm generation and operation enterprises should spend more money on technology investment.

\section{Comparative analysis of an industrial chain of the financial support efficiency of wind energy}

Figure 4 shows the comparative analysis for capital raise efficiency. The analysis results are as follows:

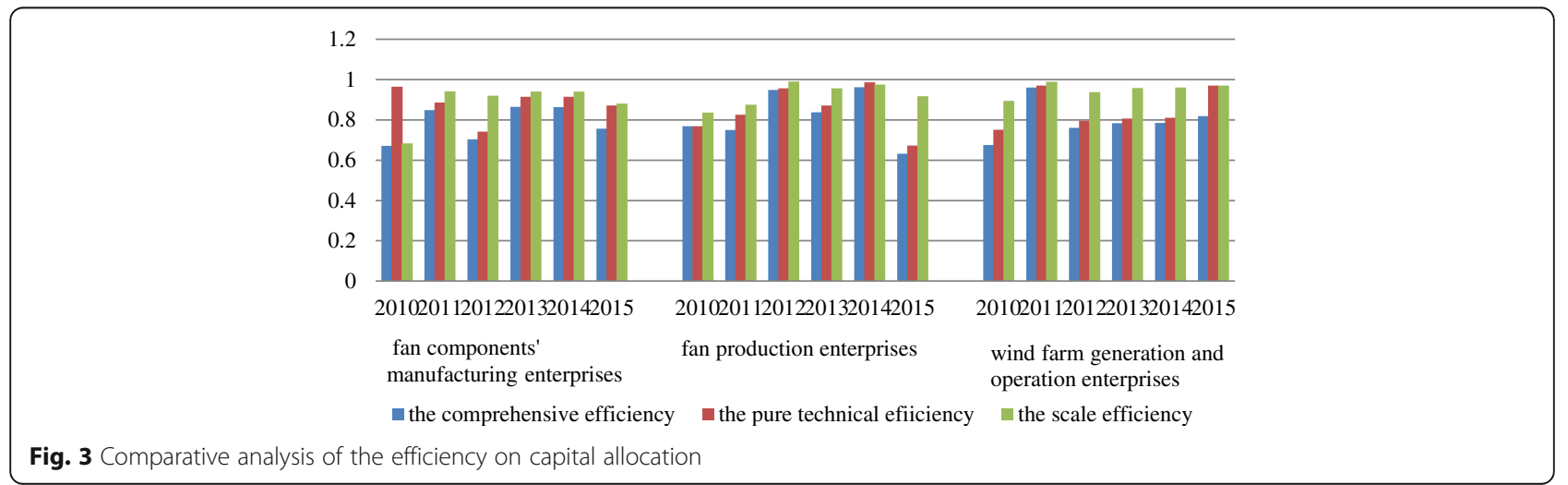




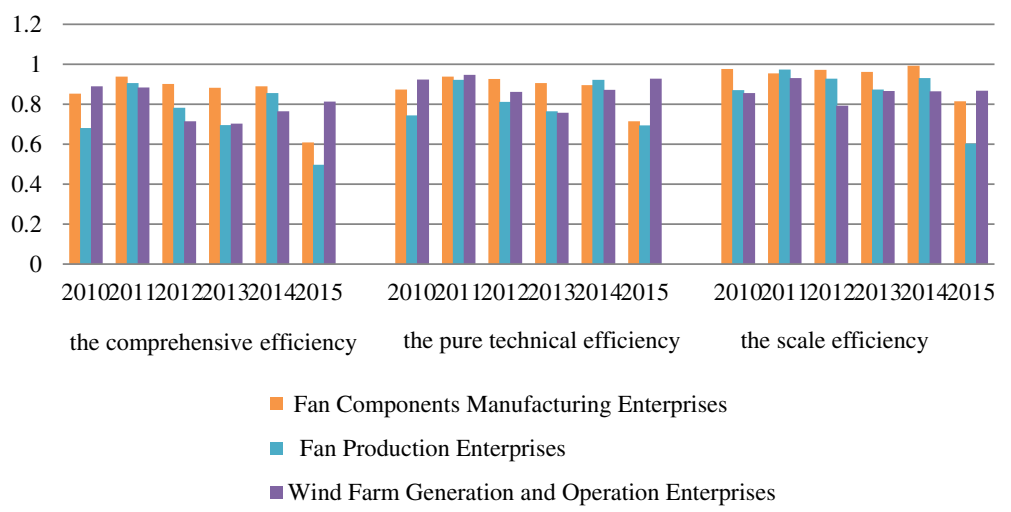

Fig. 4 Comparative analysis of the wind energy industrial chain' capital raise efficiency

1. For the comprehensive efficiency, excluding 2010 and 2015, the fan component manufacturing enterprises showed a higher comprehensive efficiency value than the other two types of enterprises, which indicated that the expansion of the wind energy industry had attracted a lot of funds, but this advantage disappeared with the realization of the financing risk. Thus the capital raise efficiency of the fan component manufacturing enterprises was mainly influenced by macro-factors; The fan production enterprises had the lowest average and that average was volatile, which demonstrated that the fund raise efficiency of the fan production enterprises was also volatile. The wind farm generation and operation enterprises maintained a relatively stable and gradually rising status which meant that the capital raise efficiency of the wind farm generation and operation enterprises were stable and not sensitive external factors.

2. For the pure technical efficiency, excluding 2014, the fan production enterprises had a lower pure technical efficiency than the other two types of enterprises, demonstrating that the fan production enterprises should pay more attention to technology investment than the other two types of enterprises in order to improve the capital raise efficiency.

3. With regard to the scale efficiency, the wind farm generation and operation enterprises indicated the lowest scale efficiency from 2010 to 2014, so that the scale investment would be the greatest concern for the wind farm generation and operation enterprises.

\section{Comparative analysis of the industrial chain capital allocation efficiency of wind energy}

Figure 5 shows the comparative analysis for capital allocation efficiency. The results of the analysis are as follows:
1. For the comprehensive efficiency, the fan production enterprises indicated a higher capital allocation efficiency than the other two types of enterprises most of the time. On the contrary, the fan component manufacturing enterprises indicated the lowest fund allocation efficiency; the capital raise efficiency of the wind farm generation and operation enterprises fluctuated slightly during the sampling period.

2. For the pure technical efficiency, excluding 2011 and 2015 , the wind farm generation and operation enterprises indicated a lower capital allocation efficiency than the other two types of enterprises. Thus, the wind farm generation and operation enterprises should spend more money on technology investment in order to improve the capital allocation efficiency.

3. For the scale efficiency, excluding 2011, the fan component manufacturing enterprises indicated a lower capital allocation efficiency than the other two types of enterprises. Thus, technology investment should be the in the focus of the fan component manufacturing enterprises.

The development of renewable energy is one way to solve the energy crisis. The wind energy industry is an important part of the renewable energy industry and has been a priority for the development of new energy strategies in the world. However, the growth of the wind energy industry has stopped and fallen to a long period of adjustments under the haze of the financial crisis in China. One of the development bottlenecks is the financing problem. Under this macroscopic background, it is very necessary to analyze the financial support efficiency of the wind energy industry in China.

The analysis of financial support efficiency of the wind energy industry is carried out in a very detailed way in this paper. First, this study thoroughly investigated the wind energy industry in the up-, middle- and down-stream chain 


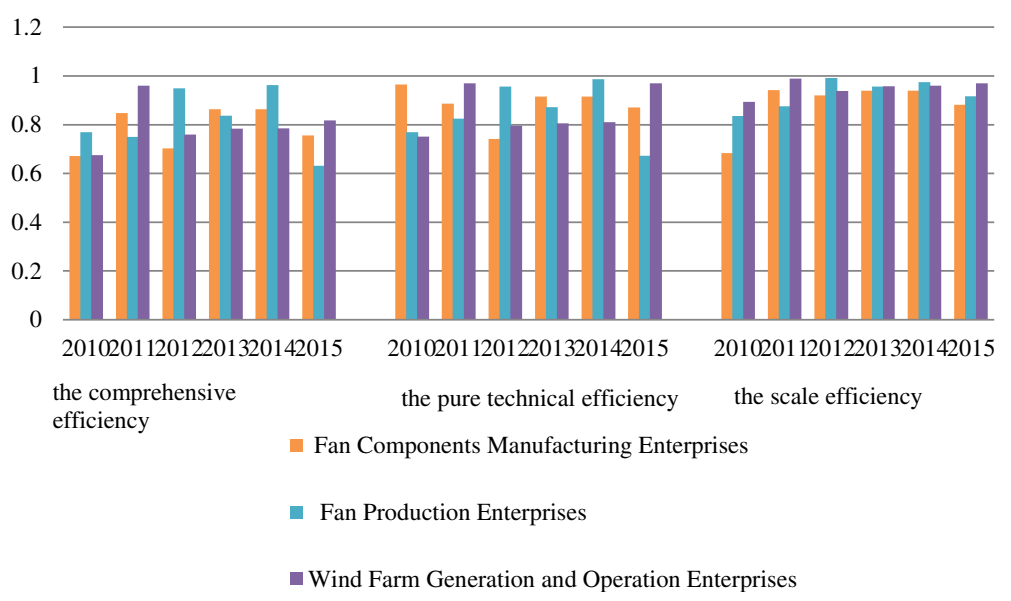

Fig. 5 Comparative analysis of the wind energy industrial chain' capital allocation efficiency

(including not only the fan component, the manufacturing enterprises and the fan production enterprises, but also the wind farm generation and operation enterprises). Furthermore, it studied the financial support efficiency from the two aspects of capital raise and capital allocation.

In this paper, the use of the DEA model represented the very basis for carrying out a further index and regression analysis for determining the more specific factors, which would affect the financial support efficiency of the wind power industry in China and provide more targeted suggestions for promoting its benign development.

\section{Conclusions}

The following conclusions could be drawn based on the analysis above.

On the whole, the overall efficiency of the financial support of the Chinese wind energy industry had a close relationship to the macroeconomic environment, also, the capital raise and the allocation efficiency of the up-, middle- and down-stream chain showed different characters. Moreover, the lag of the core technology represented the biggest barrier to the financial support efficiency of the wind energy industry.

For the fan component manufacturing enterprises, its expansion of the production scale could attract more money, but with the advent of the financial crisis, this advantage reduced rapidly, as its capital raise efficiency had a close relationship to the macro-economic environment. Therefore, the fan component manufacturing enterprises should pay more attention to technology investment in order to improve its capital raise efficiency. Regardless of a change in the macroeconomic environment, the technical level was a major factor for improving its capital allocation efficiency. Thus, the fan component manufacturing enterprises should concentrate on their capacity of technology innovation, digestion and absorption.
The fund raise efficiency of the fan production enterprises was volatile, as the capital preferred to enter the construction of the wind farm rather than the production of the fans during the financial crisis of the wind energy industry. The scale expansion of the fan production enterprises cannot attract stable capital. Instead, its investment scale was appropriate for capital allocation efficiency. Therefore, fan production enterprises should strengthen their research and development of new technology and products.

The capital raise efficiency of the wind farm generation and operation enterprises was always higher than those of the other two types of enterprises, even during the financial crisis. Moreover, its scale expansion could attract more investments. The wind farm generation and operation enterprises should therefore increase investments in technology if they wish to improve their capital allocation efficiency.

Apart from improving the wind power industries own technology and scale, for enhancing the efficiency of the financial support for the wind power industry, a corresponding policy support is needed. FIT (Feed-in-Tariff), for example, are a kind of new energy subsidies, where their purpose is to encourage investors to invest in the new energy field, as the cost of new energy technology and production is higher than that of the traditional energy sources. Governments should adopt FIT, as the new energy would be able to reduce the greenhouse effect and carbon emissions and has important environmental and social effects.

Using the FIT policy, a government can improve not only the price of wind power and eventually improve the wind product prices in various fields of the power industry, but also improve their profit margins and encourage the development of the wind power industry. On the other hand, another characteristic of FIT are the subsidies which should be provided less and less as time goes 
on. The government has to encourage investors to invest in this new energy field, and also intend to reduce the production costs of the industry step by step. In addition, the government should encourage enterprises to carry out technology research and development, improve processes and reduce the production costs by cutting the amount of subsidies year by year in order to reach a final level which competes with traditional energy costs.

\section{Abbreviation}

DEA: data envelopment analysis; DEAP version 2.1: data envelopment analysis program version 2.1; DMUs: decision-making units

\section{Acknowledgments}

The authors are grateful for the support provided by the Technical and Economic Research Institute of Business School in Hohai University.

\section{Authors' contributions}

LW and HL designed and performed the experiments; LW collected the data; all authors wrote the paper. Both authors read and approved the final manuscript.

\section{Competing interests}

The authors declare that they have no competing interests.

\section{Publisher's Note}

Springer Nature remains neutral with regard to jurisdictional claims in published maps and institutional affiliations.

\section{Author details}

'Business School, Nanjing Xiaozhuang University, Hongjing Avenue 3601, Nanjing, Jiangsu 211171, People's Republic of China. 'Business School, Hohai University, Xikang Road 1, Nanjing, Jiangsu 210098, People's Republic of China.

Received: 30 September 2016 Accepted: 8 November 2017

Published online: 04 December 2017

\section{References}

1. Li JF (ed) (2012) China wind power outlook 2012. China Environmental Science, Beijing

2. Liu QZ, Chen SY (2010) The development and utilization of China's renewable energy. Val Eng 22(2):245-262 (In Chinese)

3. Xu F, Zhou WH (2014) The performance evaluation of financial support for new energy industry based on DEA and logit methods. Sci Tech Manag Res 20(8):33-38 (In Chinese)

4. Cory K, Coughlin J, Jenkin T, Pater J, Swezey B (2008) Innovations in wind and solar PV financing, National Renewable Energy Laboratory, Collins. https://doi.org/10.2172/924986

5. David G.M (2009) Opportunities in wind, solar and infrastructure financial. The equipment leasing and finance association's (ELFA) 48th annual convention, San Diego, 18th October 2009

6. Lee W (2009) Financial renewable energy in today's capital market. George K Baum and Company, Sacramento

7. Frølunde SG, Obling PE (2010) Valuation models for wind farms under development. Copenhagen Business School, Denmark. Available via DIALOG. http://studenttheses.cbs.dk/handle/10417/1080. Accessed 7 July 2010

8. Wu QG (2010) The development and utilization of China's renewable energy. Environ Sci Manag 33(1):122-123 (In Chinese)

9. Zhong $\mathrm{SZ}$, He H (2011) Joint tenant mode of wind power project financing lease. Chin Power Ent Manag 7(1):52-53 (In Chinese)

10. Nikos DL, Matthew GK, Maria KP (2015) Stochastic life-cycle cost analysis of wind parks. Reliab Eng Syst Safe 144:117-127

11. Laura CS, Vicente DC (2014) Life-cycle cost analysis of floating offshore wind farms. Renew Energ 66(6):41-48

12. Campoccia A, Dusonchet L, Telaretti E, Zizzo G (2008) Financial measures for supporting wind power Systems in Europe: a comparison between green tags and feed' in tariffs. In: 2008 international symposium on power electronics, electrical drives, automation and motion, Ischia, 11 June 2008

13. Bolinger M, Wiser R (2006) A comparative analysis of business structures suitable for farmer-owned wind power projects in the United States. Energ Policy 34(14):1750-1761

14. Ozkan D, Duffey MR (2011) A framework for financial analysis of offshore wind energy. Wind Eng 35(3):267-288

15. Zhou D, Zhao XG (2015) Industrial performance of the renewable resources industry in China. Sustainability 7(9):11777-11798

16. Xiong ZD, Lin X (2010) Industrial performance of the renewable resources industry in China. Econ Manag 11:26-33 (In Chinese)

17. Sueyoshi T, Goto M (2013) A use of DEA-DA to measure importance of R\&D expenditure in Japanese information technology industry. Decis Support Syst 54(2):941-952

18. Suo RX, Wang FL (2009) Evaluation of the effectiveness of financial support to agriculture based on the DEA method. J NE Agric University 19(3):46-51

19. Tong MF (2011) The research of performance evaluation of automotive listed companies based on DEA model. Dissertation, China University of Geosciences, Beijing (In Chinese)

20. Pang RZ, Zhang Y, Xue W (2007) Factors affecting the operating efficiency of Chinese listed banks-an analysis based on two-step tobit regression model. Fin Forum 10:29-35 (In Chinese)

21. Charnes A, Cooper W, Rhodes E (1978) Measuring the efficiency of decision making units. Eur J Oper Res 2(6):429-444

\section{Submit your manuscript to a SpringerOpen ${ }^{\circ}$ journal and benefit from:}

- Convenient online submission

- Rigorous peer review

- Open access: articles freely available online

- High visibility within the field

- Retaining the copyright to your article

Submit your next manuscript at $\gg$ springeropen.com 